\title{
Investigations of SAW Structures with Oxide Graphene Layer to Detection of Selected Gases
}

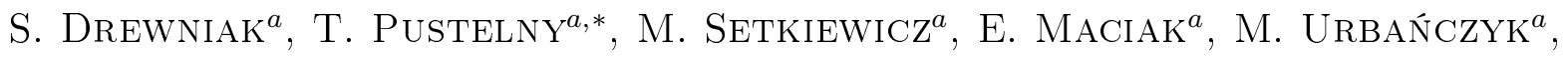 \\ M. ProceK ${ }^{a}$, Z. OPILSKI ${ }^{a}$, J. JAGIELLO ${ }^{b}$ AND L. LiPINSKA ${ }^{b}$
}

${ }^{a}$ Department of Optoelectronics, Silesian University of Technology, Akademicka 2, 44-100 Gliwice, Poland

${ }^{b}$ Institute of Electronic Materials Technology, Wólczyńska 133, 01-919 Warsaw, Poland

\begin{abstract}
In this paper we present the results of investigations of graphene oxide layers using the SAW structure (structure with surface acoustic wave propagated) exposed to the affect of low concentrations of hydrogen and nitrogen dioxide in synthetic air. During the measurements, the differential signal (from two measuring channels) was recorded. The sensing graphene oxide layer was deposited only on first channel, whereas the second channel was not covered by any additional layer. The tests were made with various concentrations of the analyzed gases and at various temperatures of the sensing structure during the measurements. Analyses were performed with special emphasis on the time response of the sensor structure to changes in the gas atmosphere.
\end{abstract}

DOI: $10.12693 /$ APhysPolA.124.402

PACS: 42.81.Pa, 82.47.Rs, 07.07.Df

\section{Introduction}

In recent years, researches related to harmful effects of the gases emitted in various industrial processes as by-products have been very popular, due to the necessity of complying with environmental standards [1-6]. Thus better and more accurate solutions ought to be found. One of the gases, which must be monitored (e.g. in a nuclear reactor [7]) is hydrogen. Hydrogen is explosive at concentrations from $4 \%$ to $75 \%$ in air [8] and an additional difficulty to detect it is that hydrogen is colorless and odorless. Other gases, important with respect to safety, are ammonia, carbon dioxide and nitrogen dioxide. Measurements of the concentration of ammonia is particularly important in agriculture and in refrigeration technology [9], also often used in medical diagnostics and food processing [10]. The control of the concentration of carbon dioxide is necessary in biological and medical researches [11], whereas nitrogen dioxide, among others because of causing acid rain in consequence of its merging with the steam, should be classified as a serious environmental problem 2, 12].

For the detection of the selected gases, various properties of the sensor are taken into account (e.g. optical, electrical properties). It is also important to choose proper sensing layers. Carbon-based materials seem to be a good solution, which has been confirmed in many scientific articles [13-16]. An additional advantage of sensors based on carbon materials is the low temperature of their operation [17]. Beyond resistive sensors [9, 19-21], sensors with an acoustic wave play an important role in detecting the selected gases $[2,4]$. Such sensors are characterized

*corresponding author; e-mail: Tadeusz.Pustelny@polsl.pl by a high sensitivity. This paper presents the results of tests of the structure with an surface acoustic wave (SAW) affected by hydrogen and nitrogen dioxide.

\section{Preparation of the structure}

Interdigital transducers for SAW generation were made on plates of a lithium niobate crystal. The interdigital transducers were manufactured in a lift-off multi-stage processes. The width of aluminum electrodes and interval between them are equal to $5 \mu \mathrm{m}$. The sensor layer (graphene oxide) was deposited only on one channel of the structure (the second channel called reference channel was not covered by any additional layer). Graphene oxide was prepared by means of the modified Hummers method [8]. The structure can be seen in Fig. 1 .

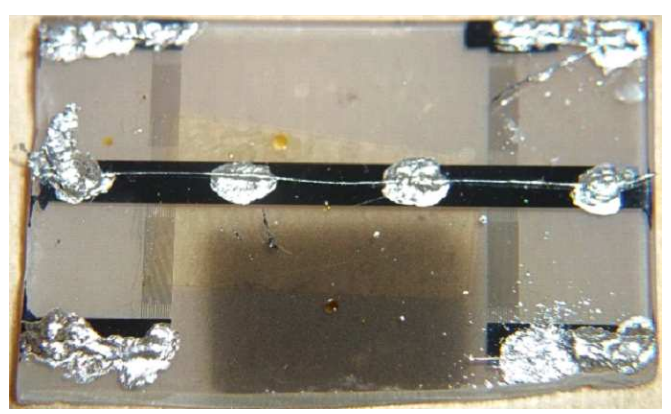

Fig. 1. Image of the sensing structure.

The images of topography, phase shift and Raman spectra of graphene oxide are shown in Figs. 2 and 3. Measurements of the graphene oxide tests made use of the atomic force microscopy and Raman spectroscopy applying N-TEGRA Prima (AFM) and N-TEGRA Spectra (Raman spectroscopy) produced by NT-MDT Co. 
In order to obtain the photography of the surface, the HA_NC tip was used. The length of the laser light which was used in the Raman spectroscopy measurements was equal to $532 \mathrm{~nm}$. Both the images of the topography of the surface, phase shift and Raman spectra, obtained before and after contacting the sensor structure with the analyzed gas atmosphere, do not differ significantly; therefore in this paper we present only the images obtained after all cycles of measurements had been finished.

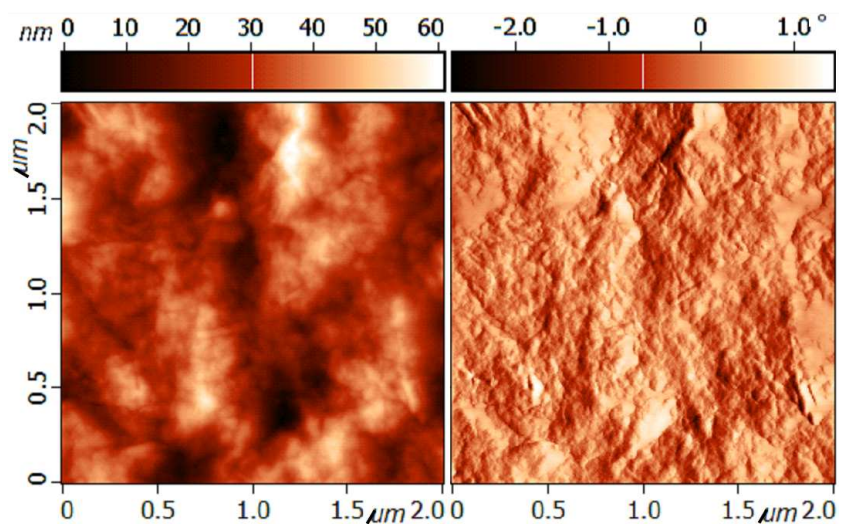

Fig. 2. Topography (left) and phase shift (right) of the structure (area of the graphene oxide).

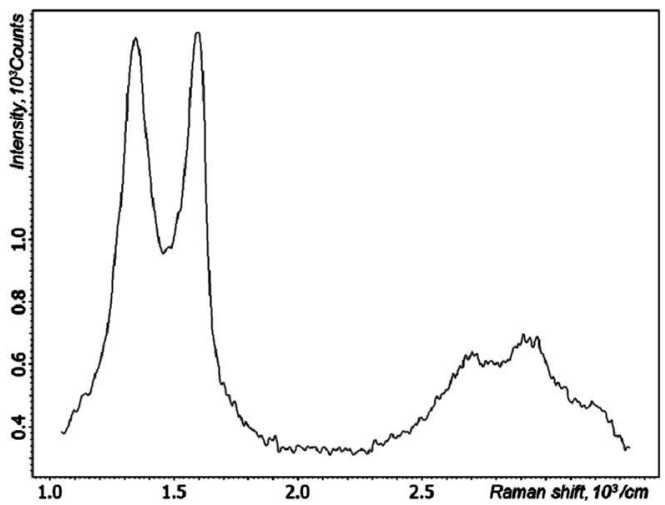

Fig. 3. Raman spectra of graphene oxide on the lithium niobate.

\section{Sensitivity of the structure affected by hydrogen}

The purpose of the first experiments was to investigate whether it is possible to detect the hydrogen in air atmosphere and what is the limit level of this detection. First, hydrogen (4\% concentration in synthetic air) was dosed alternately with synthetic air. During one cycle of measurements, the structure was heated up from $40^{\circ} \mathrm{C}$ to $120^{\circ} \mathrm{C}$ in steps of $20^{\circ} \mathrm{C}$. During the measurements, the differential signal $\Delta f$ (difference frequency between the channel covered with a layer of graphene oxide and the reference channel) versus the time was registered. Figure 4 presents the dependence $\Delta f_{\mathrm{D}}$ vs. time, where $\Delta f_{\mathrm{D}}=\left|\Delta f-\Delta f_{\max }\right|$, which was recorded when the temperature of the structure was equal to $120^{\circ} \mathrm{C}$. It can be seen that at $120^{\circ} \mathrm{C}$ the frequency changes during the flow of the hydrogen. A similar behavior has also been observed at lower temperatures.

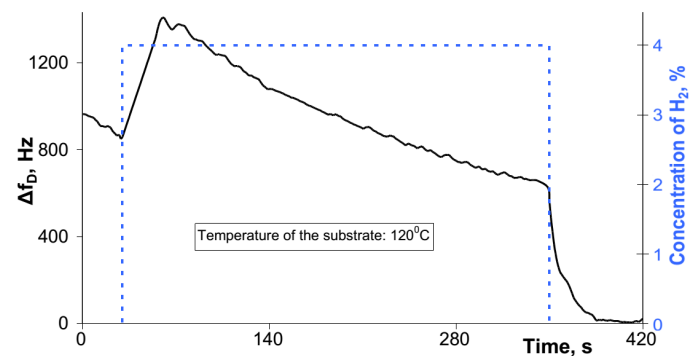

Fig. 4. Response of the structure affected by hydrogen (temperature of the sensing structure was equal to $120^{\circ} \mathrm{C}$ ).

In the next experiment the reaction of the structure, affected by various concentrations $(1 \%, 2 \%, 3 \%$ and $4 \%)$ of hydrogen in the atmosphere of synthetic air, was studied (at various temperatures of the substrate). The analyzed gas was alternately dosed with synthetic air with a moisture of about $5 \%$. Figures $5-7$ present selected characteristics $\Delta f_{\mathrm{D}}$ vs. time.

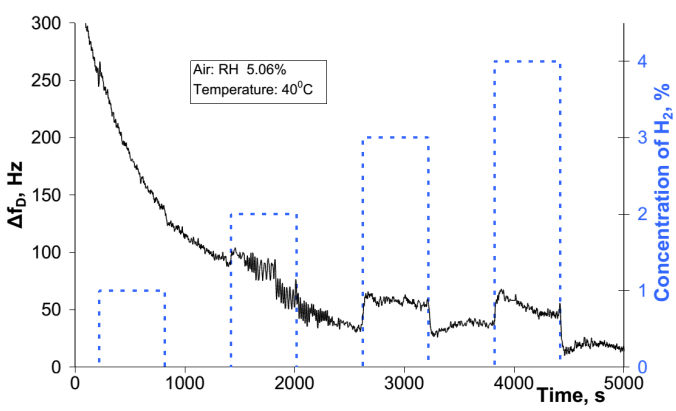

Fig. 5. Response of the structure affected by hydrogen (temperature of the sensing structure was equal to $\left.40{ }^{\circ} \mathrm{C}\right)$.

The response of the structure on hydrogen acting kept at a temperature of $40^{\circ} \mathrm{C}$, did not allow to determine the time interval, in which the hydrogen with a concentration of $1 \%$ in synthetic air was dosed. An unambiguous estimation of the time interval, when hydrogen was dosed, was only possible at a concentration of $3 \%$ and $4 \%$. It has also been shown that an increase of the concentration of the analyzed gas causes an increasing signal $\Delta f_{\mathrm{D}}$. Measurement results obtained at temperatures of $80^{\circ} \mathrm{C}$ and $120^{\circ} \mathrm{C}$ allow to determine all the time intervals in which hydrogen was dosed (also in the case of dosing $1 \%$ hydrogen in synthetic air). It has also been observed that bigger changes were recorded at the temperature $120^{\circ} \mathrm{C}$ 
than at $80^{\circ} \mathrm{C}$. Changes of $\Delta f_{\mathrm{D}}$ signal increase with the increasing concentration of hydrogen in synthetic air.

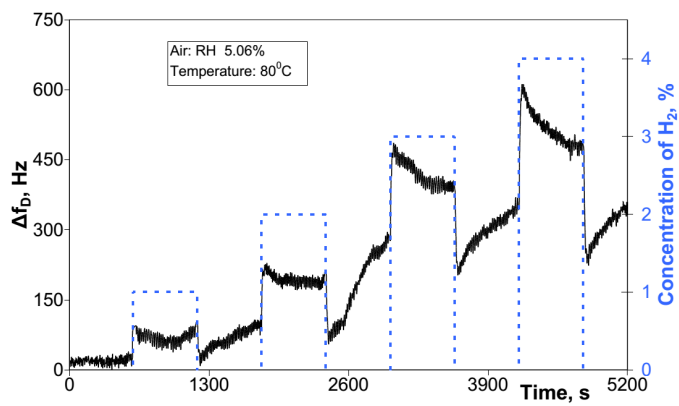

Fig. 6. Response of the structure affected by hydrogen (temperature of the sensing structure was equal to $80^{\circ} \mathrm{C}$ ).

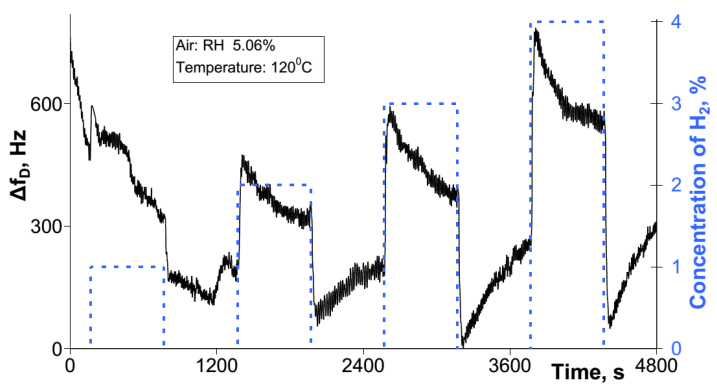

Fig. 7. Response of the structure affected by hydrogen (temperature of the sensing structure was equal to $\left.120^{\circ} \mathrm{C}\right)$.

\section{Sensitivity of the structure affected by nitrogen dioxide}

In the next stage of measurements, the sensing structure was affected by various concentrations $(125,250$, 375 , and $500 \mathrm{ppm}$ ) of nitrogen dioxide in synthetic air. Figures 8 and 9 show the results of experiments, in which the substrate was kept at a $50^{\circ} \mathrm{C}$ and $120^{\circ} \mathrm{C}$.

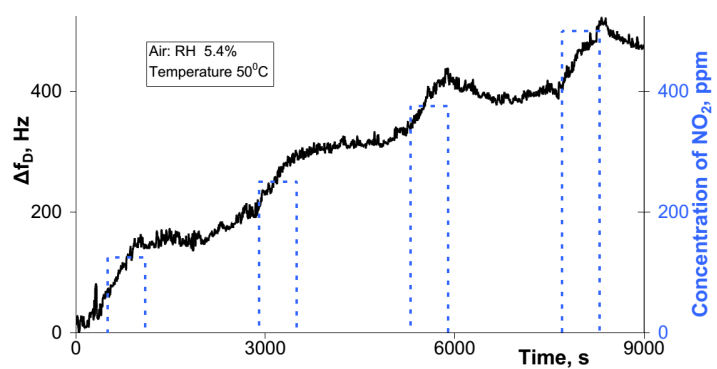

Fig. 8. Response of the structure affected by nitrogen dioxide (temperature of the sensing structure was equal to $\left.50^{\circ} \mathrm{C}\right)$.

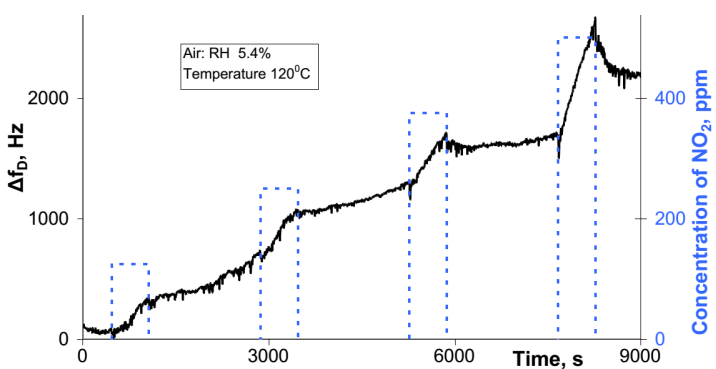

Fig. 9. Response of the structure affected by nitrogen dioxide (temperature of the sensing structure was equal to $120^{\circ} \mathrm{C}$ )

The frequency $\Delta f_{\mathrm{D}}$ is increased during the dosing of nitrogen dioxide at both $50{ }^{\circ} \mathrm{C}$ and $120^{\circ} \mathrm{C}$; the changes of the signal are however significantly higher at a higher temperature (which is clearly visible in Fig. 10, where the characteristics shown in Figs. 8 and 9 are compared). Additionally, it should be noted that the changes of the frequency $\Delta f_{\mathrm{D}}$ increase with the increasing concentration of nitrogen dioxide in synthetic air.

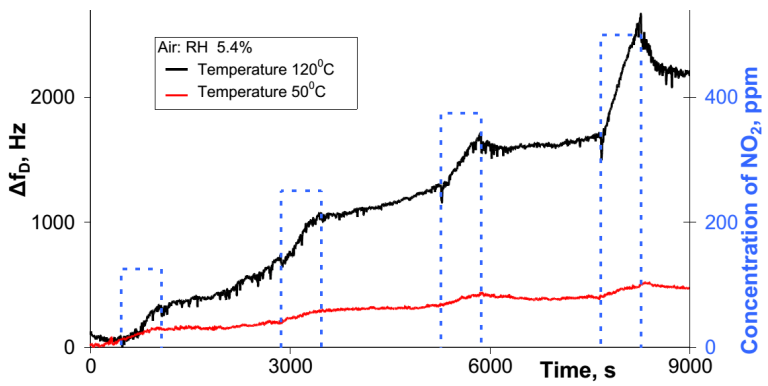

Fig. 10. Response of the structure affected by nitrogen dioxide (temperature of the sensing structure was equal to $50{ }^{\circ} \mathrm{C}$ and $120^{\circ} \mathrm{C}$ )

\section{Summary}

The SAW sensing structure based on graphene oxide allows to detect the low concentration of hydrogen and nitrogen dioxide in the atmosphere of synthetic air. Both for hydrogen and nitrogen dioxide, the signal $\left(\Delta f_{0}\right)$ changes are bigger for higher temperatures of graphene oxide (in measured range). Additional advantage of the presented sensor is its low working temperature. Comparing the changes of the $\Delta f_{0}$ signals registered during the contact of the structure with analyzed atmosphere, it can be seen that for nitrogen dioxide in synthetic air the changes were bigger than for hydrogen in synthetic air.

\section{Acknowledgments}

S. Drewniak, M.Sc., received a scholarship in the project DoktoRIS - Scolarship Program for the Innovation of Silesia co-financed by the European Union within the European Social Fund. 
M. Procek, M.Sc., is a scholar of the "SWIFT (Scholarships Supporting Innovative Technology Forum)" project POKL.08.02.01-24-005/10 co-financed by the European Union within the European Social Fund.

The investigations were sponsored by the National Centre for Scientific Researches and Development (NCBiR) within the grant O R00 017912.

\section{References}

[1] K. Gut, Bull. Pol. Acad. Sci., Techn. Sci. 59, 395 (2011).

[2] A. Kawalec, K. Jasek, M. Pasternak, Eur. Phys. J. ST 154, 123 (2008).

[3] E. Maciak, Z. Opilski, T. Pustelny, M. Bednorz, J. Phys. IV:JP (France) 129, 131 (2005).

[4] J. Filipiak, L. Solarz, G. Steczko, Acta Phys. Pol. A 120, 598 (2011).

[5] K. Gut, Opt. Appl. 42, 407 (2012).

[6] T. Pustelny, I. Zielonka, C. Tyszkiewicz, P. Karasinski, B. Pustelny, Opto-Electron. Rev. 14, 161 (2006).

[7] T. Hubert, L. Boon-Brett, G. Black, U. Banach, Sensors Actuators B 157, 329 (2011).

[8] B. Chu, J. Nicolosi, C.F. Lo, W. Strupiński, S.J. Pearton, F. Ren, Electrochem. Solid-State Lett. 14, K43 (2011).

[9] T. Pustelny, M. Setkiewicz, S. Drewniak, E. Maciak, A. Stolarczyk, M. Urbańczyk, M. Procek, K. Gut, Z. Opilski, I. Pasternak, W. Strupinski, Bull. Pol. Acad. Sci.: Techn. Sci. 61, 293 (2013).

[10] L.Q. Nguyen, P.Q. Phan, H.N. Duong, C.D. Nguyen, L.H. Nguyen, Sensors 13, 1754 (2013).
[11] N.B. Borchert, J. Kerry, D. Papkovsky, Sensors Actuators B 176, 157 (2013).

[12] A. Sharma, M. Tomar, V. Gupta, Sensors Actuators $B$ 181, 735 (2013).

[13] A. Kaniyoor, R.I. Jafri, T. Arockiadoss, S. Ramaprabhu, Nanoscale 1, 382 (2009).

[14] T. Pustelny, M. Setkiewicz, S. Drewniak, E. Maciak, A. Stolarczyk, M. Procek, M. Urbańczyk, K. Gut, Z. Opilski, I. Pasternak, W. Strupiński, Acta Phys. Pol. A 122, 870 (2012).

[15] B.H. Chu, C.F. Lo, J. Nicolasi, C.Y. Chang, V. Chen, W. Strupinski, S.J. Pearton, F. Ren, Sensors Actuators B 157, 500 (2011).

[16] Z. Bielecki, J. Janicki, A. Kawalec, J. Mikolajczyk, N. Palka, M. Pasternak, T. Pustelny, T. Stacewicz, J. Wojtas, Metrology Measur. Systems 19, 3 (2012).

[17] L.S. Zhang, W.D. Wang, X.Q. Liang, W.S. Chu, W.G. Song, W. Wang, Z. Wu, Nanoscale 3, 2458 (2011).

[18] M. Gautam, A.H. Jayatissa, Mater. Sci. Eng. C 31, 1405 (2011)

[19] T. Pustelny, M. Procek, E. Maciak, A. Stolarczyk, S. Drewniak, M. Urbańczyk, M. Setkiewicz, K. Gut, Z. Opilski, Bull. Pol. Acad. Sci.: Techn. Sci. 60 , 853 (2012).

[20] A. Reina, H. Son, L. Jiao, B. Fan, M.S. Dresselhaus, Z. Liu, J. Kong, J. Phys. Chem. C112, 17741 (2008). 